\title{
Prevalence of overweight, obesity and thinness among adolescents in rural and urban areas of Enugu State, Nigeria
}

\author{
Ani P. $\mathrm{N}^{1 *}$, Uvere P. $\mathrm{O}^{2}$, Ene-Obong H. $\mathrm{N}^{3}$ \\ ${ }^{I}$ Department of Home Science, Nutrition \& Dietetics. University of Nigeria, Nsukka \\ ${ }^{2}$ Department of Food Science \& Technology. University of Nigeria, Nsukka \\ ${ }^{3}$ Department of Biochemistry (Nutrition unit). University of Calabar, Calabar, Cross River State, Nigeria \\ *Corresponding author's E-mail: peace.ani@unn.edu.ng
}

\begin{abstract}
Background: Overweight and obesity in adolescence are powerful risk factors of chronic diseases in adulthood. Objective: To determine the prevalence of overweight, obesity and thinness among adolescents in rural and urban areas of Enugu State, Nigeria.

Method: A total of 500 adolescents (10-19 years) consisting of 220 males and 280 females were randomly selected from 12 study schools in the State. A structured questionnaire was used to collect data on background information of the adolescents. Anthropometric measurements (weight and height) of the adolescents were obtained, and used to calculate the Body Mass Index (BMI). The BMI were categorized into obesity, overweight, normal and thinness using the International Obesity Task Force (IOTF) reference and the WHO adult BMI classification for adolescents up to 19 years. The data obtained were coded and analyzed into means, frequencies, percentages and chi-square using the Statistical Package for Social Sciences (SPSS), version 17.

Results: The prevalence of overweight, obesity and thinness among adolescents were $7.5 \%$. $2.1 \%$ and $13.9 \%$, respectively. The prevalence of obesity among the adolescents in urban areas was $4.1 \%$ while none of the rural adolescents was obese. There was a higher prevalence rate of obesity among males than among females.

Conclusion: Obesity is creeping into traditional societies as evident in this study.
\end{abstract}

Keywords: Adolescents, Nigeria, obesity, overweight, prevalence, thinness.

\section{Introduction}

Adolescence is a stage of maturation between childhood and adulthood and a critical period characterized by rapid growth and change with respect to physical, cognitive and social development [1]. The World Health Organization defines adolescence as the period between the ages of 10 to 19 years [2]. Significant weight gain generally begins between ages 5 and 7, during puberty or during the teenage years [3]. Diet and nutrition clearly play a critical role during this period of development. The rapid changes in physical growth and psychological development place adolescents as a nutritionally vulnerable group with unhealthy eating behaviors $[4,5]$. The adverse health consequences of overnutrition in adolescence can be severe and often are not fully reversible [6]. Takomana and Kalimbra [7] noted that rapidly changing lifestyles (sedentary) and calorie-rich diets are increasing the occurrence of overweight and obesity which are the most important modifiable risk factors of chronic diseases. Overweight and obesity have been singled out as the major nutrition and public health problems especially in the early stages of life (childhood and adolescence). Overweight and obesity often result from an imbalance between energy intake and energy expenditure, thereby resulting to excesses which are stored in adipose tissues. This is a pathological derangement in the feedback between energy intake and expenditure.

Obesity is a form of malnutrition and can be classified as juvenile-onset and adult-onset. When obesity develops in infancy or childhood, numerous adipose cells develop, each with the ability to grow large (hyperplastic obesity). In adult obesity, fewer adipose cells are usually present but these contain excess amount of fat (hypertrophic obesity). As obesity progresses in adulthood, adipose cells can increase in number [8]. Childhood obesity is a serious health threat since about $40 \%$ of obese children and about $80 \%$ of obese adolescents become obese adults [8]. Evidence suggests that if weight is well managed and kept within ideal levels, significant reduction in the burden of non-communicable disease 
and associated premature deaths can be realized [9]. A number of methods are used to determine overweight and obesity. Some are based on the relationship between height and weight, using Body Mass Index (BMI) [10] while others are based on measurement of body fat using instruments like dual energy X-ray absorptiometry [11]. There is however, a consensus that indicators based on weight and height measurements such as Body Mass Index (BMI) should be used for clinical practice and epidemiological studies in classifying body weight status. The causes of overweight and obesity are multifactorial, the most common causes include excess caloric intake [12] and reduced physical activity [13]. The environmental factor that promotes lack of physical activity and increase in the rate of fast food consumption (excessive caloric intake) is now rampant as a result of development and urban sprawl. However, nutrient deficiencies can occur concurrently with its 'excesses' within the same population resulting in both undernutrition and overnutrition [14], [15]. The coexistence of undernutrition and overnutrition within a population also referred to 'double burden of malnutrition' has enormous consequences among which are childhood mortality and chronic diseases at later age [16]. In 2004, the global prevalence of overweight and obesity among children and adolescents (5 to 17 years) was estimated by the International Obesity Task Force (IOTF) to be 10\% [17]. A national survey conducted in South Africa in 2003 found that the prevalence of overweight (including obesity) among older adolescents (15-19 years) was over 19\%, with boys less commonly overweight $(14 \%)$ than the $25 \%$ of girls [18]. In Nigeria, the prevalence of obesity among adolescents in urban and rural areas of Lagos State was reported as 3.0\% and 0.0\%, respectively [19]. A total of 18\% of Nigerian children and adolescents ( 5 to 15 years) were reported to be obese in a study carried out in 1997 by Owa and Adejuyigbe [20]. The prevalence rate of overweight, obesity and thinness among school-aged children and adolescents in Southern Nigeria were recorded as $11.4 \%, 2.8 \%$ and $13.0 \%$, respectively [21].

Trends in overweight and obesity in adolescents have been studied in only a few developing countries and sub-groups; this study was therefore conducted to determine the prevalence of obesity and overweight among adolescents in rural and urban areas of Enugu State, Nigeria.

\section{Subjects and methods}

\subsection{Study area}

This study was carried out in Enugu State, Nigeria. Nigeria is the most populous country in Africa and the seventh most populous country in the world [22]. The population of Nigeria as at December, 2011 was 162,470,737 according to World Bank and this represents $2.35 \%$ of the world's total population. Enugu State has 17 Local Government Areas (LGAs) with a total population of 3,267,837 [23]. There are 777,518 (385,304 males and 392,214 females) adolescents in the State among which 693,436 (342,042 males and 351,394 females) are in school [24]. Enugu State is made up of the 'Igbos', who make up $18 \%$ of the country's population. The 'Igbos' number about 40 million worldwide and 30 million in Nigeria. The State has a land area of approximately $7161 \mathrm{~km} 2$ that spreads from the semi-tropical rainforest belt of the south towards the Guinea savannah in the north. Their staple foods include rice (Oryza sativa), yam (Discorea spp), cowpea (Vigna unguiculata), pigeon pea (Cajanus cajan), bambara groundnut (Vigna subterranean), African yambean (Sphenostylis stenocarpa), maize (Zea mays), cassava (Manihot esculenta), cocoyam (Colocasia esculenta) and plantain (Musa paradisiaca).

\subsection{Sampling procedure}

A multi-stage sampling technique was adopted. In the first stage, Enugu State was stratified into rural and urban areas. Enugu North, Igbo-Eze North and Oji-River Local Government Areas (LGAs) were randomly selected out of the 17 LGA that make up Enugu State. According to the US Census Bureau, an urban area is a place that has a population density of 6475 or more persons per square kilometer ( 2500 or more persons per square mile). Rural area, according to the national population census of 1991, is used to describe a community with a population of less than 5000. Based on these criteria, Enugu North (Enugu Urban) was chosen to represents the urban area while Igbo-Eze North and Oji-River LGAs were chosen to represent the rural areas. In the next stage, two communities were randomly selected from each of the selected LGA through balloting. The selected communities were Ogurute, Igogoro, Ahani-Achi, Enugu-Inyi, TransEkulu and Independence layout. A list of schools in the selected communities was obtained from the State Education Commission and was stratified into private and public schools. From the list, one private and one public school were randomly selected from each of the selected communities. In the last stage, every third pupil in each class (who was within the age range of 10-19 years) was chosen for the study to give a total of 500 pupils (250 pupils from urban and 250 pupils from rural); consisting of 220 males and 280 females.

\subsection{Informed consent}

A visit was made to the selected schools to discuss the objectives and the significance of the study with the teachers and the representatives of the school's Parent-Teachers Association and to obtain approval for the study. Approval was given by the individual school authorities and the parents/guardians of selected adolescents. 


\subsection{Data collection}

A structured and validated questionnaire was used to collect data on background information of the adolescents. The ages of the selected adolescents were obtained from the school registers. Anthropometric measurements (height and weight) of the adolescents were obtained. Height was determined using a microtoise height meter rule placed on a flat floor. Participants were asked to remove their shoes and stand in front of the height meter rule with their heels, buttocks, shoulders and back of the head touching the wall. The head was comfortably erect, the lower boarder of the orbit in the horizontal plane and the external auditory meatus and the arms hanging freely at the sides in a natural manner, the height was measured and recorded to the nearest 0.1 centimeter $(\mathrm{cm})$, and was later converted to meter $(\mathrm{m})$. Weight was determined using a Hanson bathroom scale which was adjusted to zero mark after each measurement. Participants were weighed wearing minimal clothes and no footwears and the weights recorded to the nearest $0.1 \mathrm{kilogram}(\mathrm{kg})$.

The height and weight measurements were then used to calculate the BMI of the adolescents using the formula;

$$
B M I=\frac{\text { Weight }(K g)}{\operatorname{Height}^{2}\left(m^{2}\right)}
$$

The BMI were categorized into obesity, overweight, normal and thinness using the International Obesity Task Force (IOTF) reference for children [10]. For adolescents up to 19 years, the adult BMI classification of <18.5 (thinness), 18.5-24.9 (normal), $\geq 25-29.9$ (overweight) and $\geq 30$ (obese) as proposed by WHO [25] was used.

\subsection{Statistical analysis}

The data obtained were coded and analyzed into frequencies, percentages and mean using the Statistical Package for Social Sciences (SPSS), version 17. Chi-square analysis was used to determine the difference between various groups.

\section{Results}

\section{General characteristics of the adolescents}

The general characteristics of the adolescents (Table 1) showed that $44 \%$ and $56 \%$ of the respondents were male and female respectively. Up to $46 \%$ of the study population were in their early adolescence (10 -14 years) while $54 \%$ of them were in their late adolescence stage (15-19 years). Majority of the respondents were Christian (90.4\%) and Igbos $(89.6 \%)$.

Table 1: Adolescents' sex, age, religion and tribe

\begin{tabular}{|c|c|c|c|}
\hline \multicolumn{2}{|c|}{ Variables } & \multirow{2}{*}{$\frac{\text { Frequency }}{220}$} & \multirow{2}{*}{$\frac{\text { Percentage }(\%)}{44}$} \\
\hline Sex & Male & & \\
\hline & Female & 280 & 56 \\
\hline & Total & 500 & 100 \\
\hline \multirow[t]{3}{*}{ Age } & $10-14$ years & 230 & 46 \\
\hline & $15-19$ years & 270 & 54 \\
\hline & Total & 500 & 100 \\
\hline \multirow[t]{4}{*}{ Religion } & Christian & 452 & 90.4 \\
\hline & Moslem & 29 & 5.8 \\
\hline & Others & 19 & 3.8 \\
\hline & Total & 500 & 100 \\
\hline \multirow[t]{5}{*}{ Tribe } & Igbo & 448 & 89.6 \\
\hline & Hausa & 25 & 5.0 \\
\hline & Yoruba & 19 & 3.8 \\
\hline & Others (Ibibo, Ijaw) & 8 & 1.6 \\
\hline & Total & 500 & 100 \\
\hline
\end{tabular}

\section{Mean BMI of rural and urban adolescents according to age}

The BMI of rural and urban adolescents according to age is shown in Table 2. Except for 11 and 19 year old adolescents, mean BMI of urban males were higher than that of the rural males. In females, mean BMI of urban adolescents were higher than that of the adolescents in rural areas, except for the 11 year olds. This difference at age 11 years was more pronounced among the females. The urban males who were 15 years of age had the highest mean BMI value (22.4) among the males, while for their rural counterparts, apart from the lowest BMI recorded at 16 years of age, BMI increased with age and was highest at age 19 years. For the female respondents, lowest BMIs were recorded at 11 years and 10 years for urban and rural adolescents, respectively, while higher BMIs were observed from age 17 years for both urban and rural female adolescents. 
Table 2: Mean BMI of rural and urban adolescents according to age

\begin{tabular}{cccccc}
\hline & \multicolumn{2}{c}{ MALE } & \multicolumn{2}{c}{ FEMALE } & \multicolumn{2}{c}{ TOTAL } \\
AGE (years) & Urban & Rural & Urban & Rural & 482 \\
\hline 10 & 18.4 & 16.9 & 19.2 & 16.7 & 34 \\
11 & 17.2 & 17.3 & 16.5 & 19.5 & 17.9 \\
12 & 20.4 & 17.8 & 18.4 & 18.9 & 64 \\
13 & 18.2 & 16.6 & 20.3 & 20.5 & 56 \\
14 & 19.5 & 18.5 & 20.8 & 19.4 & 66 \\
15 & 22.4 & 19.2 & 21.1 & 20.9 & 67 \\
16 & 20.8 & 19.6 & 22.6 & 21.5 & 59 \\
17 & 21.7 & 20.8 & 23.2 & 21.7 & 31 \\
18 & 20.9 & 20.1 & - & 21.0 & 30 \\
19 & 20.4 & 21.1 & - & & 26 \\
\hline
\end{tabular}

Prevalence of overweight, obesity and thinness among adolescents in Enugu State, Nigeria

Fig. 1 shows that $2.1 \%$ and $7.5 \%$ of the total respondents were obese and overweight respectively while $76.5 \%$ and $13.9 \%$ of them were normal and underweight (thin) respectively.

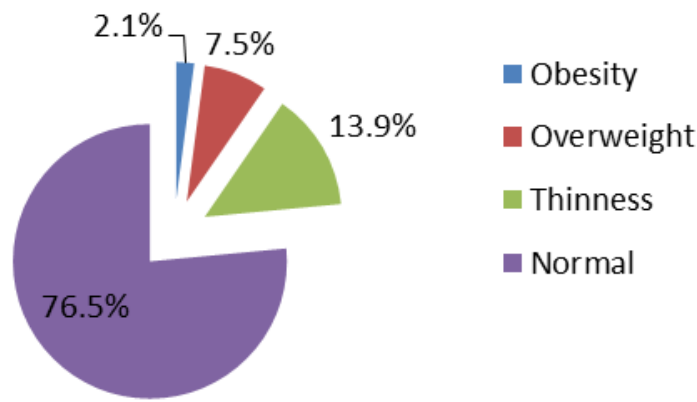

Fig. 1: Prevalence (\%) of obesity, overweight and thinness among adolescents according to age

Prevalence of obesity, overweight and thinness among adolescents according to age

The prevalence of obesity, overweight and thinness among adolescents according to age is shown in Table 3 . The prevalence of obesity $(0.8 \%)$ and overweight (1.0\%) was higher among the urban adolescents who were 15 years of age. The highest percentage of overweight recorded in rural areas was among adolescents who were $12(0.6 \%)$ and 14 $(0.6 \%)$ years of age. There was no obese adolescent at any age group in the rural area. The highest prevalence of thinness in rural area $(1.9 \%)$ was recorded among adolescents who were 11 years of age.

Table 3: Prevalence (\%) of obesity, overweight and thinness among adolescents according to age in Enugu State, Nigeria

\begin{tabular}{|c|c|c|c|c|c|c|c|c|c|}
\hline $\begin{array}{c}\text { AGES } \\
\text { (Years) }\end{array}$ & $\begin{array}{r}\text { URBAN } \\
\text { Obesity }\end{array}$ & Overweight & Normal & Thinness & $\begin{array}{l}\text { RURAL } \\
\text { Obesity }\end{array}$ & Overweight & Normal & Thinness & TOTAL \\
\hline 10 & $1(0.2)$ & $1(0.2)$ & $19(3.9)$ & $4(0.8)$ & - & - & $15(3.1)$ & $4(0.8)$ & 44 \\
\hline 11 & - & $1(0.2)$ & $11(2.3)$ & $6(1.2)$ & - & - & $17(3.5)$ & $4(0.8)$ & 39 \\
\hline 12 & $2(0.4)$ & $3(0.6)$ & $29(6.0)$ & $2(0.4)$ & - & $3(0.6)$ & $20(4.1)$ & $5(1.0)$ & 64 \\
\hline 13 & - & $1(0.2)$ & $27(5.6)$ & $1(0.2)$ & - & - & $20(4.1)$ & $7(1.5)$ & 56 \\
\hline 14 & $1(0.2)$ & $2(0.4)$ & $27(5.6)$ & $6(1.2)$ & - & $3(0.6)$ & $18(3.7)$ & $9(1.9)$ & 66 \\
\hline 15 & $4(0.8)$ & $5(1.0)$ & $30(6.2)$ & $1(0.2)$ & - & - & $21(4.4)$ & $6(1.2)$ & 67 \\
\hline 16 & - & $3(0.6)$ & $25(5.2)$ & $4(0.8)$ & - & $2(0.4)$ & $22(4.6)$ & $3(0.6)$ & 59 \\
\hline 17 & $2(0.4)$ & $4(0.8)$ & $6(1.2)$ & - & - & $1(0.2)$ & $18(3.7)$ & - & 31 \\
\hline 18 & - & $3(0.6)$ & $5(1.0)$ & - & - & - & $19(3.9)$ & $3(0.6)$ & 30 \\
\hline 19 & - & $3(0.6)$ & $4(0.8)$ & - & - & $1(0.2)$ & $16(3.3)$ & $2(0.4)$ & 26 \\
\hline TOTAL & 10 & 26 & 183 & 24 & - & 10 & 186 & 43 & 482 \\
\hline
\end{tabular}

Prevalence of overweight, obesity and thinness among adolescents in rural and urban areas

Table 4 shows the prevalence of overweight, obesity and thinness among adolescents in urban and rural areas. In urban area, $10.7 \%, 4.1 \%$ and $9.9 \%$ of the respondents were overweight, obese and thin, respectively. The prevalence rates of overweight and thinness in rural area were $4.2 \%$ and $18 \%$, respectively. Obesity was significantly $(\mathrm{p}<0.05)$ more prevalent among urban than among rural adolescents. There were more overweight in urban $(10.7 \%)$ than rural (4.2\%) area, however this difference was not significant $(\mathrm{p}>0.05)$. There was no significant difference in the prevalence of thinness between urban and rural adolescents. Although, thinness was not significant, the proportion of rural thin adolescents (18\%) was double the value for urban adolescents $(9.9 \%)$. 
Table 4: Prevalence of overweight, obesity and thinness among adolescents in rural and urban areas of Enugu State

\begin{tabular}{ccccc}
\hline & \multicolumn{2}{c}{ URBAN } & \multicolumn{3}{c}{ RURAL } \\
BMI Classification & Frequency & Percentage (\%) & Frequency & Percentage (\%) \\
\hline Obesity & 10 & 4.1 & - & - \\
Overweight & 26 & 10.7 & 10 & 4.2 \\
Normal & 183 & 75.3 & 186 & 77.8 \\
Thinness & 24 & 9.9 & 43 & 18.0 \\
Total & 243 & 100 & 239 & 100 \\
\hline
\end{tabular}

Prevalence of overweight, obesity and thinness among adolescents in rural and urban areas according to sex

The prevalence of overweight, obesity and thinness of adolescents in rural and urban areas by sex are shown in Table 5 . A total of $6.2 \%, 10.3 \%$ and $9.3 \%$ of the males and $2.7 \%, 11 \%$ and $10.3 \%$ of females in the urban areas were obese, overweight and thin, respectively. Obesity was not recorded among the adolescents in the rural area. There was a significant difference $(\mathrm{p}<0.05)$ between the BMI status of urban and rural males while that of females showed no significant difference. Even though there were no statistical differences, overweight and thinness were much higher among urban and rural females, respectively.

Table 5: Prevalence of overweight, obesity and thinness among adolescents in rural and urban areas according to sex

\begin{tabular}{|c|c|c|c|c|c|}
\hline \multirow[b]{2}{*}{ SEX } & \multirow[b]{2}{*}{ BMI Classification } & \multicolumn{2}{|c|}{ URBAN } & \multicolumn{2}{|c|}{ RURAL } \\
\hline & & Frequency & Percentage $(\%)$ & Frequency & Percentage $(\%)$ \\
\hline \multirow[t]{6}{*}{ MALE } & Obesity & 6 & 6.2 & - & - \\
\hline & Overweight & 10 & 10.3 & $\overline{3}$ & $\overline{2}$ \\
\hline & Normal & 72 & 74.2 & 97 & 79 \\
\hline & Thinness & 9 & 9.3 & 23 & 19 \\
\hline & Total & 97 & 100 & 123 & 100 \\
\hline & & $\chi^{2}=16.8$ & $=0.001$ & & \\
\hline \multirow[t]{5}{*}{ FEMALE } & Obesity & 4 & 2.7 & - & - \\
\hline & Overweight & 16 & 11 & $\overline{7}$ & 6.0 \\
\hline & Normal & 111 & 76 & 89 & 76.7 \\
\hline & Thinness & 15 & 10.3 & 20 & 17.2 \\
\hline & Total & 146 & 100 & 116 & 100 \\
\hline
\end{tabular}

\section{Discussion}

A good number of the adolescents in this study are Igbo. This is quite expected considering that the study area (Enugu State) is a part of Igbo ethnic group in Nigeria. The high prevalence of overweight $(7.5 \%)$ and obesity $(2.1 \%)$ among the adolescents indicates that there is an increasing trend in this global epidemic, considering the lower prevalence recorded across African countries about a decade ago [26]. The rapid development witnessed in this State in recent years must have contributed to the change in eating habits and sedentary lifestyle among this age group, which manifested in increased weight gain. This trend is however, at variance with the trend in a few recent studies [27], [28] carried out in Nigeria which recorded a lower prevalence of both overweight and obesity. The lower prevalence could be a function of the different criteria used in the BMI classification, hence the need to harmonize international standards for adolescent BMI classification. Alternatively, it may be due to genetic differences.

A higher prevalence of overweight and obesity was reported in urban $(10.7 \%, 4.1 \%)$ than rural areas $(4.2 \%, 0 \%)$ in the present study. This could be as a result of urbanization and higher socioeconomic status of the families in urban areas and exposure to junk convenience foods, much of which are dense in calories. In contrast, the rural dwellers are not economically buoyant and at the same time consume traditionally and locally produced foods which are minimally processed and in many areas have a relatively larger content of vegetables. Another, reason could be due to the increased physical demands characteristic of rural agrarian lifestyle. The prevalence of rural obesity in this present study was similar to that reported in a study carried out in Lagos, Nigeria among adolescents aged 10 to 19 years [19]. At the same time, thinness seem to be more prevalent in rural $(18 \%)$ than urban $(9.9 \%)$ area indicating a function of location. This agrees with the study by Ene-Obong et al. [21] in Southern Nigeria and WHO report [29] that children in the poorest households are twice as likely to be underweight as those in the least poor households.

A slightly higher prevalence of overweight $(11.4 \%)$ and obesity $(2.8 \%)$ compared to this study was reported among urban children and adolescents aged 5-18 years by Ene-Obong et al. [21], however the values for thinness were similar. This difference could be a function of location as the previous study was conducted exclusively in urban areas. 
Urbanization has been linked to exposure to junk foods and sedentary lifestyles which are contributory factors in excessive weight gain, as noted earlier.

The prevalence of overweight and obesity among adolescents in urban areas was highest at 15 years. The prevalence of overweight and obesity in both rural and urban areas tended to decrease after 15 years of age. This could be because as the adolescents grow into late adolescence, they become more conscious of their body weight and tend to control it in order to avert stigmatization among peers and low self-esteem associated with weight gain [30], [31].

Another important finding of this study was that more than half of the obese adolescents were male as had also be reported in 2006 by Bener [32] among Qatari adolescents. The higher prevalence of obesity among adolescent males in this study may be related to their tendency to eat voraciously in order to meet the rapid growth needs and to be seen to belong to an elite group. On the contrary, the females had lower prevalence because they are more conscious of their appearance and body shapes. This trend is in contrast to studies done in Nigeria [21], [33] and some other parts of the world [34], [35] where prevalence of obesity was reported to be higher in female than male adolescents. Adolescent females in this study had a higher prevalence of overweight than males. The difference in the prevalence of obesity and overweight among adolescent males and females shows that gender differences in body fat mass could be attributed to the difference in natural distribution of fat between males and females especially at adolescence [36], [37].

A growing number of developing countries experience a double burden of malnutrition which manifest as undernutrition, along with a rapid rise in overweight, obesity and diet-related chronic diseases at later age. The prevalence of thinness recorded in this study shows that irrespective of the growing prevalence of overweight and obesity among adolescents in the State, underweight is also significant indicating the coexistence of both overnutrition and undernutrition as stated earlier. The prevalence of thinness in this study was similar to that reported by Ene-Obong et al. [21] for school-age children and adolescents in Southern Nigeria. The emerging problems of overweight in some countries in Africa have been historically linked to the burden associated to undernutrition.

\section{Conclusion}

The results of this study have shown that overweight/obesity is creeping into traditional societies despite this; underweight is still a problem as evident in Enugu State. In view of this, early recognition of excessive weight gain relative to linear growth is essential. Therefore, there is need to target adolescents through nutrition education programmes in order to encourage physical activity, healthy eating habits and guard against heavily marketed energydense fatty foods and sugary drinks. Programmes such as these should also take into consideration the different socioeconomic backgrounds of the adolescents for effectiveness.

\section{References}

[1] J. Brug, K. Wepp, Children and adolescents. In Lawrence M, Worsely T. (eds). Public health nutrition from principle to practice. McGraw Hill, New York, USA, 2007, pp 100-126.

[2] WHO, Global consultation of friendly health service consensus statement. Geneva: World Health Organization; 2001.

[3] R. Moran, Evaluation and treatment of childhood obesity. American Family Physician 59(4) 1999 861-868.

[4] Z. Shi, N. Lien, B. N. Kumar, G. Holmboe-Ottesen, Socio-demograghic differences in food habits and preferences of school adolescents in Jiangsu province, China, European Journal of Clinical Nutrition 59 (2005) 1439-48.

[5] G. S. Savige, K. Ball, A. Worsley, D. Crawford, Food intake patterns among Australian adolescents, Asia Pacific Journal of Clinical Nutrition, 16(4) 2007 738-747.

[6] B. Koletzko, V. de la Gueronniere, A. M. Toschke, R. Von Kries, and Nutrition in children and adolescents in Europe: What is the scientific basis? British Journal of Nutrition 92 (2004) S67-73.

[7] G. Takomana, A. Kalimbira, Weight gain physical activity and dietary changes during the seven months of first-year university life in Malawi, South African Journal of Clinical Nutrition 25(3) 2012 132-139.

[8] G. Wardlaw, M. Kessel, Perspectives in Nutrition, 5th edn. McGraw Hill Companies, New York: USA, 2002.

[9] P. Shetty, J. Schmindhuber, Introductory lecture: The epidemiology and determinants of obesity in developed and developing countries, International Journal of Vitamin Nutritional Research 76(4) 2006 157-162.

[10] T.J Cole, M. C Bellizzi, K. M. Flegal, W.H. Dietz, Establishing a standard definition for child overweight and obesity worldwide: International survey, British Medical Journal 320 (2000) 1240-1243. Available online: http://bmj.bmjjournals.com/cgi/reprint/320/7244/1240

[11] N. R. Shah, E. R. Braverman, Measuring adiposity in patients: The utility of body mass index (BMI), percentage body fat, and leptin, Plos One 7(4) 2012 e33308.

[12] A. Golay, E. Bobbioni, The role of dietary fat in obesity, International Journal of Obesity 21(suppl 3) 1997 S2-S11.

[13] T. Ganley, C. Sherman, Energy metabolism and obesity, Medical Clinic of North America 84 (2000) 333-346.

[14] D. T. Ha, E. J. Feskens, P. Deurenberg, B. L. Mai, N. C. Khan, F. J. Kok, Nationwide shifts in the double burden of overweight and underweight in Vietnamese adults in 2000 and 2005: two national nutrition surveys. BMC Public Health 11 (2011) 62. Available at: http://www.biomedcentral. Com/1471-2458/62/. Accessed 12 July 2013.

[15] N. C. Khan, H. H. Khoi, Double burden of malnutrition: the Vietnamese perspective. Asia Pacific Journal of Clinical Nutrition 17 (2008)1168.

[16] R. Shrimpton, Double Burden of Malnutrition. Available at http:/tulane.edu/publichealth/internut/upload/08-04.pdf. Accessed 12 October 2013.

[17] T. Lobstein, L. Baur, R. Uauy, Obesity in children and young people: a crisis in public health, Obesity Review 5(suppl 1) 2004 4-104.

[18] The South African Medical Research Council and OrcMacro, South African Demographic and Health Survey 2003, Department of Health, Pictoria, South Africa 2007. 
[19] U. P Ben-Bassey, A. O. Oduwole, O. O. Ogundipe, Prevalence of overweight and obesity in Eti-Osa LGA, Lagos, Nigeria, Obesity Review 8(6) 2007 475-479.

[20] J. A. Owa, O. Adejuyigbe, Fat mass, fat mass percentage, body mass index, mid upper arm circumference in a healthy population of Nigerian children, Journal of Tropical Pediatrics 43 (1997) 13-9.

[21] H. Ene-Obong, V. Ibeanu, N. Onuoha, A. Ejekwu, Prevalence of overweight, obesity and thinness among urban school-aged children and adolescents in southern Nigeria, Food Nutrition Bulletin 33(4) 2012 242-250.

[22] Library of Congress. Country profile: Nigeria. Retrieved 13th December 2012, http://lcweb.loc.gov/frd/cs/profiles/Nigeria.pdf, 2008 pp 1-23.

[23] National Population Commission. Official Gazette, 2006 census, The Federal Republic of Nigeria, Abuja: Nigeria 96(2) 2009 B1-B42.

[24] National Population Commission, 2006 Population and housing census of the Federal Republic of Nigeria: Population and housing Tables 1 (2006).

[25] WHO, Obesity: Preventing and managing the global epidemic, Report of a WHO Consulation on obesity. Geneva: World Health Organization; 1998

[26] Y. Wang, T. Lobstein, Worldwide trend in childhood overweight and obesity, International Journal of Pediatric Obesity 1 (2006) 11-25.

[27] I. O. Senbanjo, K. A. Oshikoya, Physical activity and body mass index of school children and adolescents in Abeokuta, Southwest Nigeria, World Journal of Pediatrics 6 (3) $2010217-222$.

[28] V. O. Omuemu, C. E. Omuemu, The prevalence of overweight and its risk factors among adolescents in an urban city in Edo State, Nigerian Journal of Clinical Practice 13(2) 2010 128-133.

[29] WHO 2013, Underweight in children. Available at http://www.who.int/gho/mdg/poverty_hunger/underweight. Accessed 12 October 2013.

[30] K. Hesketh, M. Wake, E. Waters, Body mass index and parent-reported self-esteem in elementary school children: Evidence for a causal relationship, International Journal of Obesity 28 (2004) 1233-1237.

[31] R. M. Puhl, K. D.Brownell, Bias, discrimination and obesity, Obesity Research 11 (2001) 1033-1039.

[32] A. Bener, Prevalence of obesity, overweight and underweight in Qatari adolescents, Food Nutrition Bulletin 27 (2006) 39-45.

[33] S. A. Adegoke, W. A. Oluwu, O. O. Adeodu, J. B. Elusiyan, I. O. Dedeke, Prevalence of overweight and obesity among children in Ile-Ife, South-western Nigeria, West African Journal of Medicine 28(4) 2009 216-221.

[34] A. M. Al-Sendi, P. Shetty, A. O. Musaiger, Prevalence of overweight and obesity among Bahraini adolescents: a comparison between three difference sets of criteria, European Journal of Clinical Nutrition 57(3) 2003 471-474.

[35] B. Mohammadpour-Ahranjani, A. Rashidi, M. Karandish, M. R. Eshraghian, N. Kalantari, Prevalence of overweight and obesity in adolescent Tehrani students, 2000-2001: an epidemic health problem, Public Health Nutrition, 7 (2004) 645-648.

[36] P. Deurenberg, J. A. Weststrate, J. C. Seidel, Body mass index as a measure of body fatness: age-and sex-specfic prediction formulas, British Medical Journal 65 (1991) 105-114.

[37] M. Mast, I. Kortunger, E. Konig, M. J. Muller, Gender difference in fat mass of 5-7 years old children, International Journal of Obesity 22 (1998) 878-887. 